\title{
ÉTICA REFLEXIVA Y ÉTICA DE RESPONSABILIDAD EN MAX WEBER
}

1

Cabe considerar desde un punto de vista nihilista que el mundo se encuentra regido por un irracionalismo ético. Para el asceta que quiere independizarse de las tentaciones que el mundo ofrece, toda regla ética mundana es muestra de un orden contingente, en cuyo respecto no cabe una preferencia moral auténtica (WG 332). Este nihilismo ético extremo es raro: en Grecia era atribuido a personajes algo insólitos como Hegesias (Diógenes Laertius II, 93-94) o Enesidemo en su décimo tropo (Sexto Empírico, Pyrr. Hyp. I, 145-160); místicos y ascetas orientales habrían asumido actitudes parejas, apunta Weber (WG 331). Pero, la convivencia social requiere de ciertas pautas compartidas y, por lo tanto, el nihilista ético extremo será marginado como un caso anómalo cuya rareza confirma, por decir así, la normalidad del acatamiento corriente de por lo menos ciertas normas éticas. Ello supone que el hombre normal acata y respeta ciertas reglas y, por ende, rechaza, desconoce o repudia otras. En otros términos, para el hombre social no todas las reglas éticas (usos, reglas morales, normas jurídicas) son válidas $u$ obligatorias. Por ende, el universo normativo (ético) del hombre en sociedad presupone cierta mínima racionalidad lógica, aquélla que excluye un orden ético inconsistente donde cualquier norma sería a priori válida. El problema de los órdenes morales inconsistentes ha alarmado a los moralistas, por cierto, sin que se ocuparan demasiado, con todo y a diferencia de los juristas, de los problemas lógicos involucrados.

Una sociedad política no puede constituirse a partir de un conjunto de códigos normativos inconsistentes, aunque sean sustentados por respetables moralistas nihilistas. Y ello, por definición. En el caso extremo, se constituiría un régimen enteramente anárquico, es decir, un régimen en que toda norma puede ser válida $\mathrm{y}$, por ende, donde normas contradictorias rigen simultáneamente, aunque no puedan lograr eficacia conjunta, por cuanto este mundo físico que 
habitamos no admite en su realidad de hechos contradictorios. Por lo tanto, todo orden social, en cuanto regido por un conjunto de normas, idealmente consistentes y materialmente compatibles, tiene alguna racionalidad interna que cabe desentrañar. Esa racionalidad interna es puramente circunstancial: en una cierta situación concreta dada, el estatuto normativo de los casos posibles tiene que ser suficientemente consistente; ello no vale, en cambio, cuando consideramos la historia de un grupo humano como un conjunto altamente contingente de situaciones. La historia no tiene un hilo racional único, aunque los hechos que la constituyen guardan, para ser entendibles, cierta racionalidad intrínseca.

La vida social es el campo donde se desarrollan las actividades políticas, cuyo producto es el derecho: las normas jurídicas expresan los valores (es decir, las preferencias colectivas) que han de imponerse, como normas válidas, en una sociedad que les da acatamiento suficiente en sus comportamientos efectivos. Para que esas preferencias o valores puedan hacerse efectivos se requiere que las normas que las formulan guarden aquel mínimo de racionalidad intrínseca. Vale decir: la racionalidad de las acciones sociales se manifiesta en su llamado «sentido objetivo», esto es, en el derecho, en el conjunto de normas positivas válidas que expresan las preferencias sociales predominantes que tienen un grado suficiente de eficacia posible.

2. Es bien sabido que fue Max Weber quien hizo temático el problema de la racionalidad de las acciones sociales y, en especial, quien ensayó una distinción importante entre los tipos de racionalidad jurídica. Pero, sea ello como fuere, las acciones sociales y las normas jurídicas pueden ser objeto también de juicios éticos, no sólo en el sentido de que cualquier sujeto puede juzgarlas ateniéndose a los criterios subjetivos morales que sustente, sino en el sentido más importante de que la relación que quepa establecer entre tales normas y las acciones reguladas y ciertos principios éticos hacen a una propiedad esencial del derecho, que Weber denominó «legitimidad». Las acciones, así, pueden ser consideradas racionales no sólo teleológicamente (zweckrational), en cuanto son causalmente adecuadas para alcanzar ciertos fines, sino axiológicamente racionales (wertrational) en cuanto, como las acciones morales kantianas, se fundan en normas (deberes) que el actor considera de por sí válidas, sean cuales fueren sus consecuencias (WG 12/13). Si el sujeto considera debida la acción A, pero la omite, su acción es normativamente irracional, tanto como la de quien, pretendiendo alcanzar un cierto objetivo, no lleva a cabo los actos causalmente necesarios para lograrlo. La racionalidad teleológica depende, pues, de regularidades naturales: 
sería irracional pretender tocar el cielo con el dedo, por ejemplo. La racionalidad normativa o axiológica, en cambio, es en principio puramente subjetiva, pues depende de nuestras preferencias subjetivas. Señala Weber que cuando una preferencia axiológica (subjetiva) se convierte en un «valor absoluto» -esto es, en una preferencia universal necesaria, noción casi contradictoria-, la acción que se oriente de ese modo pasa a ser llanamente irracional (WG 13). Por ende, una convicción moral con pretensión de universalidad sería objetivamente (socialmente) imposible, pues no existe un sujeto universal cuya preferencia axiológica sea de tal tipo: no cabe pensar un sujeto trascendente o trascendental cuyas preferencias sean materiales y, sin embargo, analíticamente necesarias. Sólo el sujeto individual tiene preferencias valorativamente válidas, pero las mismas carecen, por definición, de pretensión de validez intersubjetiva. Por lo tanto, queda analíticamente excluido que, con respecto a una cierta circunstancia, sólo quepa preferir siempre una acción A, quedando excluida a priori su omisión.

2. Conforme a una ética de la responsabilidad, eine Verantwortungsethik, que sirve para juzgar las acciones desde el punto de su valor teleológico, por sus resultados, una acción política es éticamente irracional cuando es causalmente fallida: se habrían propuesto como obligatorias acciones que no son medios adecuados para alcanzar un cierto objetivo. El error ético se reduce a una estrategia práctica inadecuada, como en el caso típico de un programa político fallido por no ajustarse «a la realidad». Pero, para una ética reflexiva, eine Gesinnungsethik, ¿política o jurídicamente, puede una acción legalmente regulada ser axiológicamente desvaliosa, fuera del sentido banal en que algún sujeto la considere no debida moralmente? ¿La racionalidad jurídica requiere consistencia con las valoraciones morales, como se suele afirmar, por ejemplo, tratándose de derechos humanos? O ¿una política destinada a efectivizar los derechos humanos debe atender más bien a la eficacia de los medios puestos en juego y declarados obligatorios?

3. El asunto es, como siempre, el problema de la moralidad de la política y el problema cercano de las relaciones entre derecho y moral. Weber propuso, en un discurso célebre, considerar a la política tanto como un oficio (Beruf), como una vocación, jugando con el doble sentido de la palabra alemana. En efecto, el Beruf no es sólo la profesión que se ejerce, sino que Berufen, claro, significa, estar llamado a algo, ser convocado y, en consecuencia, ocuparse de aquello para lo que se ha sido convocado. El Beruf es también la vocación. Las dos grandes vocaciones posibles del hombre social son la política o la ciencia, la praxis y la theoría, para retomar términos prestigiosos 
y enigmáticos del pensamiento griego clásico. La política, para Weber, es por de pronto toda actividad conductora (PB 5) y, en especial, la actividad de conducción de un grupo social, como el estado. Y como los estados modernos se caracterizan específicamente por el monopolio de la fuerza, la política hace al régimen de la fuerza, a su gobierno o conducción.

Resulta que en los estados modernos las pautas normativas que regulan los actos estatales son básicamente normas jurídicas: la legitimidad moral de un acto político está dada en principio por su legalidad, por su conformidad con normas jurídicas. Claro que no existe, parejamente, una legalidad moral -esto es: subjetivamente válida- con validez objetiva -esto es: intersubjetiva-. Los principios morales valen por definición para el sujeto moral autónomo que los produce o reconoce, y no por su instauración heterónoma. De este modo, la moralidad -el carácter ético- de los actos políticos queda reducida a su pura legalidad. $\mathrm{Y}$ dado que no existe un conciencia social, por encima de las individuales conciencias de los sujetos, una ética reflexiva sólo puede constituirse en el juicio crítico que cada sujeto formule con respecto de las normas positivas que expresan las decisiones políticas efectivas. Ahora bien, ¿cómo admitir, señala Weber, que un conductor jurídico, un Führer político, admita, por un lado, que la legitimidad (valor moral) de su poder provenga exclusivamente de la legalidad, moralmente neutra y heterónomamente instaurada y, por el otro, que sus acciones rectoras puedan quedar sujetas al juicio crítico de cualquier sujeto que reflexiona sobre tales acciones? El político, como profesional (als berufmässig), puede ser visto como el mero funcionario que cumple leyes; el político, como hombre llamado a una misión valiosa (Berufung como vocatio), no puede satisfacerse con una legitimación legalista de sus actos. Estos son valiosos de por sí; por de pronto, para la conciencia misma del conductor; el error político puede darse por no alcanzar suficientemente los resultados propuestos y de semejante error político es responsable, pero no es moralmente imputable, pues no hay una Besinnungsethik objetiva para juzgarlo. Resulta de esto una suerte de dilema ético: el político por vocación, el auténtico político, no puede aspirar a una mera legitimación por legalidad; el político por profesión, no puede invocar su vocación legitimada por sus creencias morales subjetivas, pues de él se pretende que se atenga a las normas existentes. Aquí se da ese dilema moral que Weber denomina la «paradoja ética» del político (PB 78).

4. Resulta así, destaca Weber, que si pretendemos ser gobernados por políticos con vocación, tendremos que aceptar que los equipos dirigentes auxiliares sean escogidos a través de un reclutamiento 
«plutocrático», pues el político que vive para la política tiene que buscar quien sostenga y mantenga a esos auxiliares que vivirán, no para la política, sino de la política. Pero un reclutamiento plutocrático no se produce por vocaciones individuales, por el llamado de una Besinnungsethik, sino por el cálculo de intereses que mide una Verantwortungsethik utilitarista. En cambio, el político profesional bien puede aprovechar de los sujetos con una desinteresada vocación política: es entre los miembros «idealistas» de una sociedad, por ejemplo, entre los jóvenes, que los políticos profesionales reclutan sus cuerpos de seguidores y auxiliares. De ahí, sin duda, la distorsionada imagen que la gente tiene de sus dirigentes políticos: pretende que los mismos sean políticos por vocación, políticos «idealistas», sin intereses económicos, pero de consuno exige que se comporten como políticos profesionales eficaces, cuyas necesidades económicas de alguna manera tienen que ser satisfechas. La financiación «desinteresada» de la política es problema arduo. Hace siglos, sólo los clérigos célibes satisfacían esas exigencias contradictorias: en la época moderna -apunta Weber-, son los juristas con formación universitaria (PB 29) quienes predominantemente pueden formar los equipos de los políticos de la más variada laya, tanto de los que viven para la política, como de y los que viven de ella. Los juristas, en cuanto abogados, atienden intereses, pero en cuanto universitarios, pueden mantener las apariencias del intelectual desinteresado. No es de extrañar que para tales estamentos, la de los juristas profesionales, la pauta rectora de legitimidad se reduzca frecuentemente a la pura legalidad. «El abogado moderno y la democracia moderna -afirma Weber- se copertenecen enteramente» (Der moderne Advokat und die moderne Demokratie gehören schlechthin zusammen, PB 31). Y como el abogado es experto en el manejo de intereses, mediante el diseño de procedimientos y ritos racionales -teleológicamente racionales-, la moralidad de la política tiende a ser utilitaria: es buena la política que conduce a los resultados propuestos, sean ellos cuales fueren.

La política moderna es una actividad formal (normativa) valorada por su eficacia en el manejo de los intereses de que se trate. Y el político auténtico, destaca Weber, es así el «demagogo»: «El demagogo es en Occidente, desde el estado de derecho y, plenamente, desde los regímenes democráticos, el tipo de político predominante» (PB 33), esto es, del político por vocación, del político que viene para la política, alarmante tesis que Weber pretende disimular recordando que el primer demagogo conocido fue Pericles.

Lo importante es destacar que si pretendemos contar con algo así como una justificación moral de la actividad política, con políticos con legitimidad, tenemos que poner de lado los criterios legalistas 
formales y suponer una ética subjetiva (reflexiva) en que el político por vocación se autojustifica, seguramente invocando su «misión» o cosa por el estilo. Weber agrega que, siendo el puro político un demagogo, su instrumento básico es la palabra, el discurso persuasivo: por ello, lo que más hacen los políticos es hablar y hablar, hasta el hartazgo, como durante un proceso electoral. Pero, actualmente (Weber se refiere al año 1919), pesa más la palabra impresa. De ahí que el verdadero político vocacional, el demagogo autojustificado, sea ante todo el publicista y el periodista que, curiosamente también, hacen de sus vocaciones una profesión. De ahí que demagogos, periodistas y abogados carezcan, destaca Weber, de un status social preciso. Todos ellos son, de algún modo, «responsables» en algún sentido, aunque no moralmente responsables (PB 34).

5. Siguiendo estas agudas observaciones de Weber sobre la política y sus factores, conviene señalar que nuestro autor procede a efectuar sus análisis recurriendo a diversos dualismos: política como vocación y política como profesión, acción política teleológica y acción política axiológicamente fundada, racionalidad formal y racionalidad material, ética de la responsabilidad y ética reflexiva, etcétera. En algunos casos pareciera que estos dualismos corresponden a características empíricas, mientras que en otros se trata más bien de construcciones teóricas más o menos clasificatorias.

Algunos de estos dualismos -legalidad y legitimidad- reflejan los antiguos dualismos entre normas jurídicas y principios morales y pretenden definir de alguna manera sus relaciones sin incurrir en hipóstasis innecesarias o en la postulación de entidades abstractas como los valores. Quizá estos dualismos, los tradicionales y los introducidos por Weber, reflejan una arcaica modalidad de pensamiento occidental, ejemplarmente manifestada en la dialéctica platónica.

Pero es en la figura, compleja y paradójica, del político donde estos dualismos aparecen con mayor rigor. Weber aclara, una y otra vez, que no cabe entender los dualismos apuntados como meras particiones lógicas; no se trata de taxonomías empíricas, sino más bien, dice, de tipos ideales configurados con propósitos explicativos (verstehend). De ahí que ningún político sea un puro demagogo que vocacionalmente hace política por la política misma, o un interesado profesional que vive de aquella política que dice defender. Ningún político incurre en la paranoia de considerar que la explotación profesional que hace de la política contradice los mandatos éticos de su conciencia, exigencias morales que pueden llevarlo hasta el sacrificio para cumplir su misión autoimpuesta.

De todas maneras, los dilemas sustantivos que Weber destaca no pueden ser resueltos con el mero análisis, explicativo o comprensivo, 
de las acciones políticas de individuos concretos. Las relaciones entre política y moral, sean ellas las que fueren, no se agotan en las circunstancias personales de los políticos. Aparece aquí, me parece, una estructura más compleja que conviene comenzar a desentrañar. Habermas, por ejemplo, que ha dedicado demasiadas páginas de su farragoso opus magnum a la racionalidad social en Weber, destaca que la distinción entre moral y derecho no sólo es un factor de racionalización social, sino que la «automatización del derecho y la moral» constituye el factor central en «el nacimiento de la sociedad moderna» (TKH 219). Pero, en ese respecto, la racionalidad formal del agente social se limita, en cuanto sujeto de una Besinnungsethik, a una cierta consistencia entre sus preferencias valorativas. En lo que hace, en cambio, a la racionalidad práctica material, se requiere de una «conducción metódico-racional de la vida» (eine methodischrationale Lebensführung), propia del Berufmensch (del hombre profesional), en que se respete la racionalidad instrumental en la utilización de medios, junto a una racionalidad electiva (de preferencias) en la selección de alternativas de acción y una racionalidad normativa consistente (TKH 232-235). Como estamos en el terreno de una Verantwortungsethik, Habermas subraya -como el propio Weber lo había destacado- que no es posible superar el relativismo ético consecuente, sino asumirlo; Habermas destaca que ese relativismo «vuelve a plantearse en el plano metateórico», aun cuando se lo rechace en el plano teórico (TKH 243).

6. El sujeto moral propiamente dicho, aquél que puede dar validez a una Besinnungsethik, es, por definición, el hombre en cuanto individuo. Las reglas de esas éticas reflexivas valen en cuanto es el sujeto que se sujetaría a ellas quien las ha producido: el sujeto de una Besinnungsethik es, en definitiva, el sujeto autónomo de la ética de Kant. Pero del conjunto de individuos autónomos no cabe lograr principios éticos -esto es: reglas de conducta- de validez universal, válidas para cualquier sujeto, salvo incurriendo en ficciones metafísicas como el sujeto trascendental de la ética kantiana. Para un sociólogo sólo existen individuos empíricamente dados, hombres históricamente individualizados. Ciertamente ningún grupo humano cuenta con una conciencia trascendental constituyente de sus códigos normativos, aunque ciertamente todos los grupos humanos tienen recursos procesales mediante los cuales acuerdan o convienen cuáles reglas reconocen. El derecho escrito constituye una muestra clara de reglas sociales -esto es: de validez objetiva, supraindividualartificialmente producido. La moral o los valores absolutos, en cambio, aunque sean acordados por muchos, no por eso alcanzan la necesaria validez requerida por normas obligatorias: el carácter obligatorio 
de la moral es puramente subjetivo. Por tanto, puede muy bien ser que el sujeto individual reconozca y acate las normas intersubjetivamente establecidas, como las jurídicas, pero que las mismas se encuentren en conflicto, por ser incompatibles, con sus principios morales subjetivos. Si el sujeto se resigna a este problema de conciencia, en rigor está admitiendo la validez superior de las normas jurídicas sobre las morales: el derecho tiene mayor rango, como preferencia de aplicación, que la moral. Pero si el sujeto pretendiera que sus pautas morales predominen sobre el derecho heterónomamente impuesto, resultaría que estaríamos negando al derecho su característica esencial: la de contar con validez objetiva, es decir, con validez independiente de los deseos y voluntades de cada sujeto. O, en otros términos, admitir que existe derecho en una sociedad equivale a rechazar la posibilidad de la anarquía, de la situación en que cualquier norma puede adquirir validez por la voluntad imprevisible de cada sujeto. Las relaciones entre política o derecho y moral no constituyen, pues, un problema puramente teórico referente a las relaciones entre dos conjuntos normativos; las relaciones entre derecho (o política) y moral son la forma como se expresa la distribución de poderes en una sociedad. Si la moral prevalece frente al derecho, estaríamos frente a una descentralización acentuada del poder y, por ende, de una pérdida del monopolio estatal de la fuerza. Si el derecho predomina sobre la moral, la autonomía de todo sujeto quedaría sujeta a condiciones que él no controla. En todas las sociedades, dependiendo de las circunstancias concretas, esta distribución de poderes es variable. De ahí que el derecho y la política puedan ser más o menos morales, pero nunca subsumirse íntegramente en una moral absoluta, por la sencilla razón de que un conjunto de individuos no es un individuo.

7. ¿Se configura así, pregunta Weber, el ethos de la política? ¿Cuál es su lugar ético? (PB 65). ¿Cuál es «la relación real entre la ética y la política», resume Weber? (PB 67). Para una ética absoluta rige el deber de veracidad (Wahrheitspflicht). Este, sin embargo, es inadmisible para el político: como Platón ya recomendaba, el político muchas veces debe mentir para evitar consecuencias desfavorables. La mala consecuencia posible priva de validez al principio ético absoluto: puesto que «la ética absoluta no se pregunta por las consecuencias» (PB 70). Aquí radica, para Weber, el punto decisivo, sobre todo cuando las «consecuencias» postreras de las acciones políticas son recursos a la fuerza física, esto es, a la conversión del sujeto moral humano en una mera cosa. Las consecuencias coactivas de una acción política pueden consistir en privar, no sólo simbólicamente, sino realmente, al hombre de su personalidad moral, de su 
«dignidad humana». De actuar el político ateniéndose a sus propios principios morales, a su personal Besinnungsethik, resultaría que siempre la consecuencia ineludible de sus acciones es convertir a otro hombre en una cosa sin dignidad humana. Por ello, el político «moralista» es socialmente peligroso, pone en jaque la dignidad intrínseca de todos los hombres. De ahí que Weber subraye que la política sólo se relacione con una moral limitada al cálculo de intereses de los miembros de un grupo. Y ese cálculo, como se sabe, puede alcanzarse con mayor o menor racionalidad.

El sujeto de una Gesinnungsethik, el moralista autónomo productor de una moral absoluta, no puede soportar -dice Weber- la irracionalidad ética del mundo (PB 73). Ello quiere decir, en rigor, que, en cuanto moralista reflexivo, nadie soporta no ser la autoridad cósmica suprema. Nadie soporta no ser Dios. La ética reflexiva constituye, sugiere Habermas (TKH 249), la desacralización de una imagen metafísico-religiosa del mundo. Pero así como, en la realidad histórica, no somos los dioses creadores de una moral absoluta que todos tendrían que acatar «reflexivamente» (besinnend), tampoco somos responsables de todas las consecuencias que las acciones políticas producen.

El pensamiento weberiano con respecto a la moralidad de la política y de los políticos es rotundamente relativista. Ahora bien, está de moda atribuir al relativismo moral las consecuencias catastróficas del escepticismo gnoseológico radical. Cabe por de pronto apuntar que el negar la existencia de valores absolutos no equivale a incurrir en tal suerte de escepticismo: el relativismo moral es cosa menos tosca. Suponer que el relativismo ético implica, en el terreno de la moral normativa, la validez conjunta de normas contradictorias $\mathrm{y}$, por ende, la validez de toda norma sea cual fuere su contenido, conlleva una suerte de presupuestos discutibles, por ejemplo, el de que las normas tienen valor de verdad y, además, una limitación del principio de Hume, ya que se derivan normas de la falsedad analítica de enunciados descriptivos. Tal relativismo ético no es lógicamente posible y nunca ha sido propuesto. En el terreno de la metaética -que no constituye un discurso normativo-, el relativismo ético, de un Weber o de un Kelsen, se limita a sostener, como tesis descriptiva verificable, la existencia de normas contradictorias en un orden moral o jurídico. De ese conjunto de enunciados descriptivos contradictorios cabrá, quizá, extraer consecuencias arbitrarias en la metateoría, pero no establecerlas en el código normativo descripto. Lo que el relativismo ético weberiano sugiere es, sencillamente, que todo enunciado normativo promulgado (por el propio sujeto o por procedimientos sociales convenidos) es contingente, en el sentido de que su «validez», su carácter obligatorio no puede establecerse lógicamente 
(RV 68). La vida democrática no excluye para nada semejante tesis metaética, puesto que la democracia presupone que se reniega de morales dogmáticas y de derechos y políticas autoritarias.

\section{BIBLIOGRAFÍA}

J. Habermas, Theorie des kommunikativen Handelns (I: Handlugsrationalität und gesellschafstliche Rationalisierung), 1981, Suhrkamp Verlag, Frankfurt a. Main (traducción castellana: Teoría de la acción comunicativa, 1987, Taurus Ediciones, Madrid, a la que remiten las citas). Citado como TKH.

R. J. Vernengo, Éticas normativas, metaética y politicas, en Sistema 93, Revista de Ciencias Sociales, Madrid, 1988. Citado como $R V$.

M. Weber, Politik als Beruf, P. Reclam, Stuttgart, 1992, con epílogo de R. Dahrendorf. Citado como $P B$.

M. Weber, Wirtschaft und Gesellschaft: Grundriss der verstehenden Soziologie, J. C. B. Mohr, Tübingen, 1972. Citado como $W G$. 